\title{
Distributions of Sensitivities \\ to Three Sterol Demethylation Inhibitor Fungicides Among Populations of Uncinula necator Sensitive and Resistant to Triadimefon
}

\author{
Eugene O. Erickson and Wayne F. Wilcox
}

Department of Plant Pathology, Cornell University, New York State Agricultural Experiment Station, Geneva 14456. Accepted for publication 2 May 1997.

\begin{abstract}
Erickson, E. O., and Wilcox, W. F. 1997. Distributions of sensitivities to three sterol demethylation inhibitor fungicides among populations of $U n$ cinula necator sensitive and resistant to triadimefon. Phytopathology 87 : 784-791.

Single-conidial isolates of Uncinula necator from (i) a population representing two vineyards with no previous exposure to sterol demethylation inhibitor (DMI) fungicides ("unexposed," $n=77$ ) and (ii) a population representing two vineyards in which powdery mildew was poorly controlled by triadimefon after prolonged DMI use ("selected," $n=82$ ) were assayed to determine distributions of sensitivities to the DMI fungicides triadimenol (the active form of triadimefon), myclobutanil, and fenarimol. Median $50 \%$ effective dose $\left(\mathrm{ED}_{50}\right)$ values (micrograms per milliliter) in the selected versus unexposed populations were 0.06 versus 1.9 for triadimenol, 0.03 versus 0.23 for myclobutanil, and 0.03 versus 0.07 for fenarimol, respectively. Isolates were grouped into sensitivity classes according to their $\mathrm{ED}_{50}$ values, and those from the selected population were categorized as resistant if the frequency of their sensitivity class had increased significantly relative to levels found in the un-
\end{abstract}

ABSTRACT

Powdery mildew, caused by the obligate parasite Uncinula necator (Schwein.) Burrill (anamorph Oidium tuckeri Berk.), is the most important disease of grapes worldwide (23). When poorly controlled, it can lead to reduced photosynthesis (19), extensive crop loss, and reduced vine vigor (33); wine made with only a small percentage of infected berries exhibits inferior flavors (20) and aromas (33). During the early 1980s, triadimefon (Bayleton), a sterol demethylation inhibitor (DMI) fungicide, was registered in the United States to control grapevine powdery mildew and was used commonly thereafter; two additional DMIs, myclobutanil (Nova and Rally) and fenarimol (Rubigan), were registered for use by the end of the decade. All DMIs inhibit a cytochrome P-450 monooxygenase enzyme, which catalyzes part of the C-14 demethylation reaction in the ergosterol biosynthesis pathway of many fungi (35). This single-site mode of action has led to concern about development of resistance to DMIs and the likelihood of crossresistance among individual compounds in the group $(3,16)$.

The distribution of sensitivities to a DMI fungicide among individuals in an unexposed pathogen population is continuous, ranging from highly sensitive phenotypes to phenotypes considerably less sensitive (i.e., more resistant) than the population mean (13,16,36-38). Thus, exposure to a given DMI fungicide will provide selection pressure favoring the more resistant isolates in

Corresponding author: W. F. Wilcox; E-mail address: wfw1@ cornell.edu

Publication no. P-1997-0616-02R

(C) 1997 The American Phytopathological Society exposed population $\left(\mathrm{ED}_{50}\right.$ values exceeding $0.56,0.18$, and $0.18 \mu \mathrm{g} / \mathrm{ml}$ for triadimenol, myclobutanil, and fenarimol, respectively). Of the 76 isolates defined as resistant to triadimenol, 64\% were classified as crossresistant to myclobutanil, $18 \%$ were classified as cross-resistant to fenarimol, and $17 \%$ were classified as resistant to all three fungicides; $25 \%$ of the isolates classified as resistant to myclobutanil also were classified as resistant to fenarimol. Similar cross-resistance relationships were revealed when all isolates were examined by regressing $\log \mathrm{ED}_{50}$ values for each fungicide against those for the remaining two fungicides to determine the correlation coefficients (e.g., $r=0.85$ for triadimenol versus myclobutanil and 0.56 for triadimenol versus fenarimol). The restricted levels of cross-resistance indicated by these data, particularly between fenarimol and the other two fungicides, is in sharp contrast to the high levels of cross-resistance among DMIs reported for some other pathogens and has significant implications with respect to programs for managing grapevine powdery mildew and DMI resistance.

Additional keywords: fungicide resistance, grape powdery mildew, Oidium tuckeri. the population, which eventually shifts the distribution of sensitivities toward the resistant end of the spectrum $(13,16)$. Efficacy of the DMI is reduced progressively as this shift continues, and the "practical resistance" phenomenon occurs once the frequency of resistant phenotypes precludes commercially acceptable disease control under standard usage regimes $(5,13)$. Poor control of $U$. necator with DMI fungicides has been associated with such shifts in numerous California vineyards $(9,21)$. Similarly, anecdotal and documented reports of poor powdery mildew control by triadimefon in Pennsylvania (e.g., 42) and New York (24-29) have been assumed to result from the development of practical resistance to this compound in affected vineyards, although this supposition has not been proved. Neither in these examples nor in European reports of $U$. necator resistance to DMIs (39-41) has the relationship been quantified between a vineyard population's sensitivity to a DMI fungicide and the fungicide's ability to control powdery mildew in that vineyard. Correlating the magnitude of a pathogen population's shift in sensitivity to a given DMI with specific levels of diminished disease control may (i) allow assessment of the potential risk of control failure with that fungicide in other vineyards prior to initiation of control programs; (ii) provide a basis for confirming or refuting resistance as a cause of specific control problems; (iii) alert growers to the need for implementing antiresistance strategies; and (iv) provide a means of assessing the efficacy of various antiresistance strategies. To do so, it is necessary to determine and compare the sensitivity distribution of a $U$. necator population poorly controlled by the given fungicide with that of a population previously unexposed to DMI fungicides. 
Some considerations for quantifying the distribution of sensitivities to a DMI fungicide in a pathogen population are (i) individuals (i.e., clonal or single-spore isolates) must be assayed, because the collection of individual DMI sensitivities comprises the population distribution; (ii) the sample size must be sufficiently large to represent the population; and (iii) the assay method must give reproducible results. U. necator requires a living substrate, and its growth responds in a variety of ways to the substrate's condition; thus, repetitions among assays are potentially more variable than repeated assays of other pathogens that can be performed on a defined synthetic growth medium. For instance, Doster and Schnathorst (4) showed that the growth of U. necator varies significantly on leaves of different ages, and in experiments preliminary to this study, we obtained highly variable results unless strict attention were paid to maintaining a uniform age of the leaves used in sensitivity assays. Previous techniques for determining the sensitivity of $U$. necator isolates to DMI fungicides $(9,10,18,39-41)$ have addressed some, but not all, of the above concerns.

The objectives of this research were to (i) develop a reproducible method to assay individual $U$. necator isolates for sensitivity to DMI fungicides; (ii) determine the distributions of sensitivities to DMI fungicides among unexposed populations of $U$. necator versus those no longer adequately controlled by triadimefon; and (iii) investigate the degree of cross-resistance among three DMIs commonly used to control grapevine powdery mildew in the United States. A portion of this work has been published (6).

\section{MATERIALS AND METHOD}

$\boldsymbol{U}$. necator populations. Isolates of $U$. necator were collected from four vineyards: two with no previous exposure to DMI fungicides and two with suspected practical resistance to triadimefon. These specific vineyards were (i) a commercial vineyard of Vitis interspecific hybrid cv. Rougeon in Burdette, NY (Bb), in which no fungicides have been used for the previous 17 years. It is located $>3 \mathrm{~km}$ from the nearest vineyard treated with DMIs. (ii) A commercial vineyard of three V. labrusca L. cultivars in Naples, $\mathrm{NY}(\mathrm{Nb})$, in which only inorganic fungicides have been applied for 25 years. It is located $>2 \mathrm{~km}$ from the nearest vineyard treated with DMIs. (iii) A commercial vineyard of Vitis interspecific hybrid cv. Seyval near Dresden, NY (Dr), in which poor control of powdery mildew with triadimefon was first noted in 1989. Since
1992, a portion of the vineyard has been divided into replicated experimental plots, each of which has received no treatment (check) or five applications per year of either sulfur, triadimefon, myclobutanil, or fenarimol. These treatments and the control they provided are shown in Table 1. (iv) An experimental vineyard of Vitis interspecific hybrid cv. Rosette near Geneva, NY (Rr), that has been used for testing various fungicides, including a number of DMIs, since 1989. Individual plots received different treatments each year. Prior to the initiation of fungicide trials, seasonal applications of triadimefon had been used to control powdery mildew at this site annually since 1982 . The degree of powdery mildew control provided in this vineyard by triadimefon, myclobutanil, and/or fenarimol since 1989 is shown in Table 2.

Collection of $\boldsymbol{U}$. necator isolates. Approximately 60 singleconidial isolates were collected from each vineyard in 1995. Isolates were collected with an initial emphasis on obtaining discrete colonies on leaves near the head and trunk of the grapevines as soon as such symptoms, indicative of primary infections by ascospores (22), appeared in the vineyard (22). Each colony in the unexposed vineyards was collected from a separate vine, either from a block of $\sim 1,000$ vines $(\mathrm{Bb})$ or from three blocks totaling $\sim 1,200$ vines $(\mathrm{Nb})$. Colonies from the remaining two vineyards were collected from unsprayed check plots by sampling (i) 1 to 3 leaves from each of the center 2 or 3 vines in each of 4 replicate plots containing 6 to 9 vines per plot (Dr) or (ii) 16 to 17 leaves from the center 2 vines in each of 4 replicate 4 -vine plots (Rr). All colonies from the Dr vineyard were collected prior to the first spray application in nearby treated plots, whereas one to three sprays were applied (with a hooded-boom sprayer that minimized drift) to some nearby plots in the Rr vineyard prior to collection. A section of leaf containing the powdery mildew colony was cut in the field or after transport to the laboratory, transferred immediately to a $10-\mathrm{cm}$-diameter glass petri dish with $1.5 \%$ water agar (Difco Laboratories, Detroit) to retard dehydration, and incubated on the lab bench at $\sim 24^{\circ} \mathrm{C}$ for 3 days to allow additional sporulation from existing growth, after which isolates were recovered and maintained as described below.

Culture of $\boldsymbol{U}$. necator isolates. Throughout the study, U. necator isolates were cultured on 9-mm-diameter leaf disks cut with a cork borer from immature, surface-sterilized (50\% ethanol for $30 \mathrm{~s}$ ) leaves of young, greenhouse-grown $V$. vinifera L. cv. Chardonnay vines. For initial establishment and subsequent maintenance of isolates, a single conidial chain (20 to 30 total conidia) was removed from an existing colony under a dissecting microscope with

TABLE 1. Control of powdery mildew on the Vitis interspecific hybrid cv. Seyval provided by three demethylation inhibitor (DMI) fungicides in a commercial vineyard (Dresden, NY) with practical resistance to triadimefon

\begin{tabular}{|c|c|c|c|c|c|c|c|}
\hline \multirow[b]{3}{*}{ Treatment $^{\mathrm{v}}$} & \multirow[b]{3}{*}{ Rate (g a.i./ha) } & \multicolumn{6}{|c|}{ Percent tissue area infected ${ }^{w}$} \\
\hline & & \multicolumn{2}{|c|}{$1992^{x}$} & \multicolumn{2}{|c|}{$1993^{y}$} & \multicolumn{2}{|c|}{$1994^{z}$} \\
\hline & & Leaf & Cluster & Leaf & Cluster & Leaf & Cluster \\
\hline Untreated & $\ldots$ & $58 \mathrm{a}$ & $69 \mathrm{a}$ & $2.1 \mathrm{a}$ & $3.6 \mathrm{a}$ & $33 \mathrm{a}$ & $11 \mathrm{a}$ \\
\hline Sulfur & 3,587 & $12 \mathrm{c}$ & $47 \mathrm{bc}$ & $0.01 \mathrm{c}$ & $0.1 \mathrm{~b}$ & $2.9 \mathrm{c}$ & $0.2 \mathrm{~b}$ \\
\hline Triadimefon & $\begin{array}{l}105 \\
175\end{array}$ & $\begin{array}{l}31 \mathrm{~b} \\
28 \mathrm{~b}\end{array}$ & $\begin{array}{l}53 \mathrm{~b} \\
42 \mathrm{c}\end{array}$ & $\begin{array}{l}1.2 \mathrm{~b} \\
1.0 \mathrm{~b}\end{array}$ & $\begin{array}{l}2.7 \mathrm{a} \\
1.8 \mathrm{ab}\end{array}$ & $\begin{array}{l}20 \mathrm{~b} \\
17 \mathrm{~b}\end{array}$ & $\begin{array}{l}7.5 \mathrm{ab} \\
1.9 \mathrm{~b}\end{array}$ \\
\hline Myclobutanil & $\begin{array}{r}84 \\
140\end{array}$ & $\begin{array}{l}5.9 \mathrm{~cd} \\
2.2 \mathrm{~d}\end{array}$ & $\begin{array}{l}8.5 \mathrm{e} \\
2.4 \mathrm{e}\end{array}$ & $\begin{array}{l}0.02 \mathrm{c} \\
0.01 \mathrm{c}\end{array}$ & $\begin{array}{l}0.03 \mathrm{~b} \\
0.00 \mathrm{~b}\end{array}$ & $\begin{array}{l}3.1 \mathrm{c} \\
2.8 \mathrm{c}\end{array}$ & $\begin{array}{l}0.1 b \\
0.02 b\end{array}$ \\
\hline Fenarimol & $\begin{array}{l}27 \\
55\end{array}$ & $\begin{array}{l}5.9 \mathrm{~cd} \\
3.3 \mathrm{~d}\end{array}$ & $\begin{array}{l}20 \mathrm{~d} \\
8.2 \mathrm{e}\end{array}$ & $\begin{array}{l}0.01 \mathrm{c} \\
0.00 \mathrm{c}\end{array}$ & $\begin{array}{l}0.03 b \\
0.00 b\end{array}$ & $\begin{array}{l}2.8 \mathrm{c} \\
3.0 \mathrm{c}\end{array}$ & $\begin{array}{l}0.1 \mathrm{~b} \\
0.1 \mathrm{~b}\end{array}$ \\
\hline
\end{tabular}

${ }^{\mathrm{v}}$ Commercial formulations of sulfur (Microthiol 80DF), triadimefon (Bayleton 50DF), myclobutanil (Nova 40W), and fenarimol (Rubigan 1EC) were applied with a hooded-boom sprayer that delivered a volume of 1,870 liters/ha at 2,070 $\mathrm{kPa}$.

${ }^{w}$ Mean values from five replicate plots per treatment, each consisting of six vines. Fifty clusters and leaves on ten shoots were examined from the center vines of each plot during the late summer of each year. Different letters in a column represent significant differences $(P \leq 0.05)$ according to the Waller-Duncan $k$-ratio $t$ test.

${ }^{x}$ Four applications of all compounds, 15 June to 10 August.

y Six DMI and 10 sulfur applications, 26 May to 5 August.

${ }^{\mathrm{z}}$ Five DMI and 10 sulfur applications, 7 June to 1 August. 
a single camel hair attached to a glass pipette (surface-sterilized in $70 \%$ ethanol for $10 \mathrm{~min}$ and thoroughly air-dried) and transferred under another dissecting microscope to a fresh leaf disk. Inoculated leaf disks were placed in 6-cm-diameter plastic petri dishes containing $\sim 7 \mathrm{ml}$ of $1.5 \%$ water agar amended (per liter) with rifampicin $(10 \mathrm{mg})$, pimaricin $(5 \mu \mathrm{g})$, and sodium ampicillin $(150 \mathrm{mg})$ (all amendments from Sigma Chemical Co., St. Louis); the inoculated leaf disks were incubated in a growth chamber (model I30BL, Percival Scientific, Boone, IA) that was maintained at 50\% relative humidity with a 12-h light regime (Phillips [Somerset, NJ] $20 \mathrm{~W}$ cool-white fluorescent bulb, $\sim 20 \mu \mathrm{E} \mathrm{m}^{-2} \mathrm{~s}^{-1}$ ) alternating with a 12-h dark regime at 24 and $22^{\circ} \mathrm{C}$, respectively. All isolates were maintained by similarly transferring conidial chains to fresh leaf disks every 11 to 14 days. Unless otherwise noted, all fungicide assays employed the technique described above for collection and preparation of leaf-disk substrates, their inoculation with single conidial chains from fresh cultures, and their subsequent incubation in a growth chamber.

Fungicides. Technical grade triadimenol, myclobutanil, and fenarimol were obtained and stored in a freezer until used. Triadimenol is the active form of triadimefon produced in vivo by plant and fungal reduction $(1,2,8)$. It was used in lieu of triadimefon due to the latter's 500-fold greater vapor pressure (Material Safety Data Sheets, Bayer Corp., Kansas City, MO) and because preliminary studies and previous work $(2,12,30,34)$ indicated that vapor activity from triadimefon could confound the results of the assay. Fungicides were dissolved in acetone and diluted to concentrations of $31.6,10.0,3.2,1.0,0.32,0.10,0.03$, and $0.01 \mu \mathrm{g} / \mathrm{ml}$ immediately prior to each assay. All dilutions were made with distilled water containing $0.05 \%$ Tween 20 (Sigma). Because preliminary tests indicated that the highest final acetone concentration used $(\sim 0.5 \%)$ had no effect on conidial germination and hyphal growth of $U$. necator, the acetone concentration was not normalized in the dilutions.

Fungicide sensitivity assay. Effect of leaf age. Three immature leaves ( $\sim 5$ to $6 \mathrm{~cm}$ across and bright, translucent green) and three fully expanded leaves ( $\sim 12 \mathrm{~cm}$ across and dark green) five nodes below such immature leaves were harvested from separate Chardonnay vines growing rapidly in a greenhouse and were surface- sterilized. From each leaf, eight disks were cut and divided between two petri dishes, and each disk was inoculated in its center with conidia from a single $U$. necator isolate and incubated for 7 days. The maximum colony radius from the point of inoculation on each leaf disk was measured at $32 \times$ magnification with an ocular micrometer in a stereomicroscope with lateral illumination, and data were analyzed as a one-way analysis of variance (ANOVA) of leaf age with three nested leaf replications and eight subsamples per replication (Minitab, State College, PA). Coefficients of variation were calculated for the respective pooled data from immature and fully expanded leaves.

Determination of $50 \%$ effective dose $\left(E D_{50}\right)$ values. $\mathrm{ED}_{50}$ values were calculated as the measure of DMI sensitivity because they confer greater precision than other relative measurements for a given sample size (7). For each run of the assay, two or three isolates were tested against the aforementioned range of concentrations for each of the three DMI fungicides. To do so, immature Chardonnay leaves were surface-sterilized, and a sufficient number of disks was cut to provide four disks per fungicide concentration for each isolate being tested. The disks were randomized, immersed for $30 \mathrm{~min}$ in each fungicide concentration (or unamended $0.05 \%$ Tween 20 for the control) with gentle agitation every few minutes, blotted dry with filter paper, and allowed to air-dry for $\sim 5 \mathrm{~min}$. Sets of four disks from each fungicide treatment were transferred to plastic petri dishes containing antibioticamended water agar and were maintained on the lab bench for 3 to $4 \mathrm{~h}$. Each of the four replicate disks in each dish was inoculated in its center with a single isolate of $U$. necator and incubated for 7 to 8 days in a growth chamber. Fungal growth was measured as the maximum hyphal length developing from an individual conidium or as the maximum colony radius from the point of inoculation when discrete hyphae could not be identified, using an ocular micrometer at $32 \times$ magnification. Data for each fungicide concentration were expressed as mean hyphal growth relative to that on the control disks. Fungicide concentrations were transformed by adding $0.001 \mu \mathrm{g} / \mathrm{ml}$ to each (providing a log value of -3.0 for the zero-concentration control treatment), and relative growth data were plotted against the log of the appropriate transformed fungicide concentration and fit to a negative logistic regression curve

TABLE 2. Control of powdery mildew on the Vitis interspecific hybrid cv. Rosette provided by three demethylation inhibitor fungicides in a vineyard near Geneva, NY, with practical resistance to triadimefon (summarized from previous reports)

\begin{tabular}{|c|c|c|c|c|c|c|c|c|c|c|c|c|c|c|c|}
\hline \multirow[b]{3}{*}{ Treatment $^{\mathrm{p}}$} & \multirow{3}{*}{$\begin{array}{c}\text { Rate } \\
\text { (g a.i./ha) }\end{array}$} & \multicolumn{14}{|c|}{ Percent control ${ }^{\mathrm{q}}$} \\
\hline & & \multicolumn{2}{|c|}{$1989^{r}$} & \multicolumn{2}{|c|}{$1990^{\mathrm{s}}$} & \multicolumn{2}{|c|}{$1991^{t}$} & \multicolumn{2}{|c|}{$1992^{u}$} & \multicolumn{2}{|c|}{$1993^{v}$} & \multicolumn{2}{|c|}{$1994^{w}$} & \multicolumn{2}{|c|}{$1996^{\mathrm{x}}$} \\
\hline & & $\operatorname{Lf}^{y}$ & $\mathrm{Rc}$ & $\mathrm{Lf}$ & $\mathrm{Cl}$ & $\mathrm{Lf}$ & $\mathrm{Cl}$ & $\mathrm{Lf}$ & $\mathrm{Cl}$ & $\mathrm{Lf}$ & $\mathrm{Cl}$ & $\mathrm{Lf}$ & $\mathrm{Cl}$ & $\mathrm{Lf}$ & $\mathrm{Cl}$ \\
\hline Untreated & $\ldots$ & $(55)^{\mathrm{z}}$ & $(48)$ & (45) & (6.4) & (50) & (2.9) & (44) & $(50)$ & (77) & (3.4) & (90) & (37) & (76) & (31) \\
\hline Triadimefon & $\begin{array}{l}105 \\
140\end{array}$ & $\begin{array}{l}31 \\
\ldots\end{array}$ & $\begin{array}{l}56 \\
\ldots\end{array}$ & $\begin{array}{l}56 \\
\ldots\end{array}$ & $\begin{array}{l}73 \\
\ldots\end{array}$ & $\begin{array}{l}72 \\
\ldots\end{array}$ & $\begin{array}{l}93 \\
\ldots\end{array}$ & $\begin{array}{l}76 \\
79\end{array}$ & $\begin{array}{l}86 \\
72\end{array}$ & 75 & $\ldots$ & $\begin{array}{l}\cdots \\
10\end{array}$ & $\begin{array}{l}\ldots \\
68\end{array}$ & $\begin{array}{l}\ldots \\
17\end{array}$ & $\ldots$ \\
\hline Myclobutanil & $\begin{array}{r}84 \\
112\end{array}$ & $\begin{array}{l}64 \\
\ldots\end{array}$ & $\begin{array}{l}99 \\
\ldots\end{array}$ & $\begin{array}{l}97 \\
\ldots\end{array}$ & $\begin{array}{l}94 \\
\ldots\end{array}$ & $\begin{array}{l}96 \\
\ldots\end{array}$ & $\begin{array}{c}100 \\
\ldots\end{array}$ & $\begin{array}{l}\ldots \\
92\end{array}$ & $\ldots 5$ & $\begin{array}{l}\ldots \\
99\end{array}$ & $\begin{array}{l}\ldots \\
97\end{array}$ & $\ldots$ & $\begin{array}{l}\ldots \\
98\end{array}$ & $\ldots$ & $\ldots 6$ \\
\hline Fenarimol & $\begin{array}{l}27-55 \\
18-46\end{array}$ & $\begin{array}{l}75 \\
\ldots\end{array}$ & $\begin{array}{c}100 \\
\ldots\end{array}$ & $\begin{array}{l}97 \\
\ldots\end{array}$ & $\begin{array}{l}98 \\
\ldots\end{array}$ & $\begin{array}{l}86 \\
\ldots\end{array}$ & $\begin{array}{c}100 \\
\ldots\end{array}$ & $\ldots$ & $\ldots$ & $\begin{array}{l}\ldots \\
\ldots \\
\end{array}$ & $\begin{array}{l}\ldots \\
\ldots\end{array}$ & $\begin{array}{l}\ldots \\
\ldots \\
\end{array}$ & $\begin{array}{l}\ldots \\
\ldots\end{array}$ & $\begin{array}{l}62 \\
\ldots\end{array}$ & $\begin{array}{l}97 \\
\ldots\end{array}$ \\
\hline
\end{tabular}

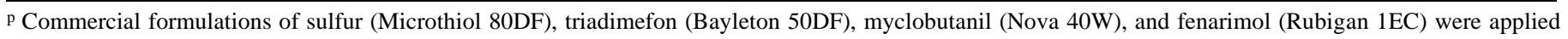
with a hooded-boom sprayer that delivered a volume of 1,870 liters/ha at 2,070 $\mathrm{kPa}$.

q Percent control was determined based on the difference in infected tissue area on sprayed versus unsprayed vines and was calculated with mean values from four replicate plots per treatment, each consisting of four vines. Leaves (15 to 25) and clusters or rachises (25 to 50) were examined from the center vines of each plot, depending on the year.

${ }^{\mathrm{r}}$ Four applications of triadimefon and myclobutanil, 3 June to 3 August, and four applications of fenarimol, 8 June to 11 August. Data excerpted from Pearson and Riegel (24).

s Five applications of triadimefon and myclobutanil, 1 June to 23 August, and four applications of fenarimol, 22 June to 23 August. Data excerpted from Pearson and Riegel (25).

${ }^{t}$ Five applications of triadimefon and myclobutanil, 3 June to 29 July, and four applications of fenarimol, 3 June to 15 July. Data excerpted from Pearson and Riegel (26).

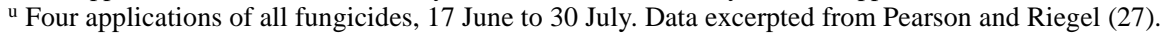

${ }^{v}$ Five applications of triadimefon and myclobutanil, 8 June to 6 August. Data excerpted from Pearson and Riegel (28).

${ }^{\text {w }}$ Four applications of triadimefon and myclobutanil, 15 June to 28 July. Data excerpted from Pearson and Riegel (29).

${ }^{\mathrm{x}}$ Four applications of all fungicides, 21 June to 2 August. Data excerpted from Wilcox and Reigel (43).

y $\mathrm{Lf}=$ leaf; $\mathrm{Rc}=$ rachis; and $\mathrm{Cl}=$ cluster.

${ }^{\mathrm{z}}$ Parenthetical values for the unsprayed treatment refer to the mean percentage of tissue area infected on check vines. 
(Genstat, Lawes Agricultural Trust, Hertfordshire, England), using the formula

$$
Y=A+\frac{C}{1+\exp [-B(X-M)]}
$$

where $Y$ represents the relative growth, $A$ represents the lower asymptote, $C$ represents the difference between the upper and lower asymptotes, $B$ represents the slope, $M$ represents the log of the concentration at the point of inflection, and $X$ represents the $\log$ concentration of a given data point. Each isolate had a set of logistic parameters for each fungicide; $\log \mathrm{ED}_{50}$ values were calculated as $X$ when $Y=0.5$ (50\% relative growth).

Assay reproducibility. Each of three isolates that originally were determined by this assay to vary widely in their sensitivities to triadimenol (i.e., $\mathrm{ED}_{50}$ values of the least and most sensitive isolates were separated by more than two orders of magnitude) were assayed nine additional times against triadimenol to determine the reproducibility and precision of the $\mathrm{ED}_{50}$ values obtained by the technique. Data were analyzed with a one-way ANOVA (Minitab).

Analysis of population sensitivities. The distribution of $\log$ $\mathrm{ED}_{50}$ values for each fungicide in each sample population was tested for normality with the Ryan-Joiner test (Minitab). For each fungicide, the sensitivity distributions from the two unexposed $U$. necator populations were tested for homogeneity of variance by Levene's test (Minitab), as were the sensitivity distributions from the two selected populations.

For each fungicide, the ability of the assay to detect a significant difference in mean $\log \mathrm{ED}_{50}$ values between any two populations was calculated as the broadest $95 \%$ confidence interval $(C I)$ of the "worst case" difference between means of two hypothetical distributions, using parameter values chosen from among the four populations ( $\mathrm{Bb}, \mathrm{Nb}, \mathrm{Dr}$, and $\mathrm{Rr}$ ). A standard formula was used for determining a $C I$ where two variances are involved:

$$
C I= \pm 2 * \sqrt{2 *\left[\frac{s_{\text {isol }}^{2}+\left(s_{\text {assay }}^{2} / n_{\text {assay }}\right)}{n_{\text {vineyard }}}\right]}
$$

where $s_{\text {isol }}^{2}$ represents the greatest variance among individual isolate $\log \mathrm{ED}_{50}$ values for the fungicide in any of the four vineyards, $s_{\text {assay }}^{2}$ represents the variance of the assay reproducibility, $n_{\text {assay }}$ represents the number of replications of each sample to determine $s_{\text {assay }}^{2}$, and $n_{\text {vineyard }}$ represents the smallest sample size of the four vineyards.

\section{RESULTS}

Assay method. Effect of leaf age. Hyphal growth of $U$. necator was 33 to $86 \%$ greater (significant at $P=0.005$ ) and less variable (coefficient of variation $=5$ to $8 \%$ versus 8 to $15 \%$ ) on disks cut from immature leaves versus disks cut from fully expanded leaves (Table 3 ). Therefore, only immature, rapidly expanding grape

TABLE 3. Effect of leaf age on growth of Uncinula necator after inoculation of excised Vitis vinifera cv. Chardonnay leaf disks

\begin{tabular}{lccccccc}
\hline & \multicolumn{3}{c}{ Immature $^{\mathrm{w}}$} & & \multicolumn{3}{c}{ Fully expanded $^{\mathrm{x}}$} \\
\cline { 2 - 3 } \cline { 7 - 8 } & Mean $^{\mathrm{y}}$ & $s$ & $\mathrm{CV}(\%)^{\mathrm{z}}$ & & Mean & $s$ & CV (\%) \\
\hline 1 & 6.5 & 0.97 & 5 & & 3.6 & 1.07 & 11 \\
3 & 5.2 & 1.19 & 8 & & 3.9 & 1.70 & 15 \\
Pooled data & 5.9 & 1.04 & 6 & & 3.5 & 0.75 & 8 \\
\hline
\end{tabular}

${ }^{\mathrm{w}}$ Immature leaves were $\sim 5$ to $6 \mathrm{~cm}$ across and bright, translucent green.

${ }^{x}$ Fully expanded leaves were $\sim 12 \mathrm{~cm}$ across, dark green, and five nodes below a similar immature leaf.

${ }^{y}$ Mean of maximum hyphal growth from point of inoculation on eight replicate disks per leaf after 7 days of incubation at 22 to $24^{\circ} \mathrm{C}$, measured in the units of an ocular micrometer at $32 \times$ magnification $(1$ unit $=312 \mu \mathrm{m})$.

${ }^{\mathrm{z}}$ Coefficient of variation (standard error per mean).
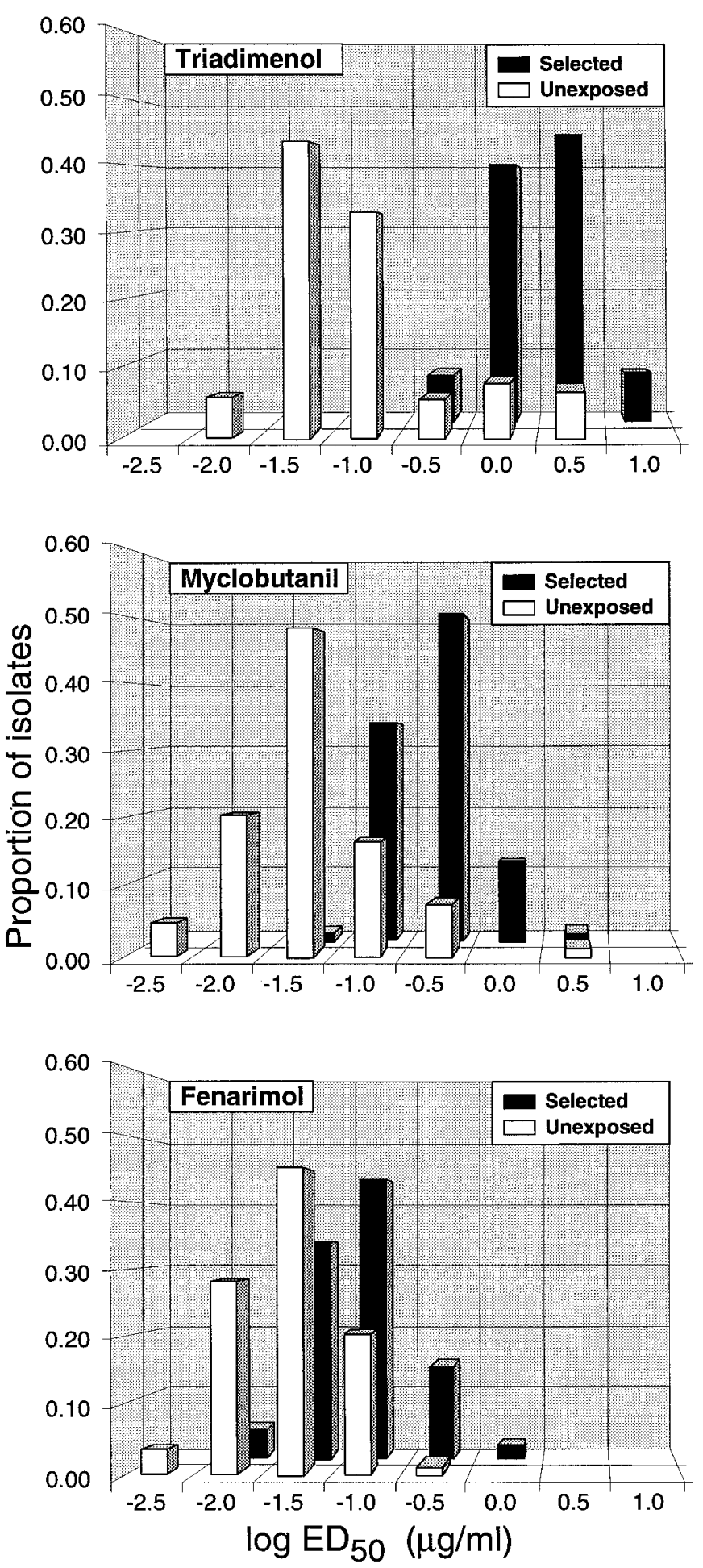

Fig. 1. Distributions of sensitivities to triadimenol (the active form of triadimefon), myclobutanil, and fenarimol among composite populations of $U n$ cinula necator (i) with no history of demethylation inhibitor fungicide exposure (unexposed, $n=77$ ) and (ii) exhibiting practical resistance to triadimefon (selected, $n=82)$. Log $50 \%$ effective dose $\left(\mathrm{ED}_{50}\right)$ values for individual isolates are organized within discrete categories, each spanning a range of 0.5 units, with the expressed value representing the midpoint of the range. The actual (antilog) $\mathrm{ED}_{50}$ values represented within the indicated $\log \mathrm{ED}_{50}$ categories are $-2.5=0.002$ to $0.006 \mu \mathrm{g} / \mathrm{ml} ;-2.0=0.006$ to $0.02 \mu \mathrm{g} / \mathrm{ml} ;-1.5=$ 0.02 to $0.06 \mu \mathrm{g} / \mathrm{ml} ;-1.0=0.06$ to $0.18 \mu \mathrm{g} / \mathrm{ml} ;-0.5=0.18$ to $0.56 \mu \mathrm{g} / \mathrm{ml} ; 0.0=$ 0.56 to $1.8 \mu \mathrm{g} / \mathrm{ml}$; and $1.0=5.6$ to $17.8 \mu \mathrm{g} / \mathrm{ml}$. For analyses of cross-resistance, individual isolates were classified as resistant to triadimenol, myclobutanil, and fenarimol if their $\mathrm{ED}_{50}$ values exceeded $0.56,0.18$, and $0.18 \mu \mathrm{g} / \mathrm{ml}$, respectively, based on the pronounced frequency increases of these categories in the selected versus unexposed populations. 
leaves were used for the fungicide assays and for maintaining the isolate collection.

Assay precision and reproducibility. Calculated and $\log \mathrm{ED}_{50}$ values varied only moderately (coefficients of variation $=13$ to $15 \%$ and pooled standard deviation $=0.210$, respectively) among nine repeated assays of three $U$. necator isolates with divergent sensitivity to triadimenol. Depending on the assay repetition, the calculated $\mathrm{ED}_{50}$ values (micrograms per milliliter) for isolates $\mathrm{Nb} 36$, $\mathrm{Nb} 17$, and Dr23 varied from 0.01 to 0.10 (mean $=0.05), 0.82$ to $2.70($ mean $=1.41)$, and 3.01 to $8.97($ mean $=5.29)$, respectively. The $95 \%$ least significant difference interval was \pm 0.17 log units, indicating that the assay could resolve isolates that differed in log $\mathrm{ED}_{50}$ values by less than the dose interval of the assay $(0.5 \mathrm{log}$ units). Thus, for some reporting and analytical purposes, isolates were grouped according to their $\log \mathrm{ED}_{50}$ values into sensitivity categories at $0.5 \log$-unit intervals, with the midpoints for each category corresponding to the concentrations used in the assay. The $95 \%$ confidence intervals for resolving differences in mean log $\mathrm{ED}_{50}$ values between vineyard populations were $\pm 0.28, \pm 0.27$, and $\pm 0.16 \log$ units for triadimenol, myclobutanil, and fenarimol, respectively, or approximately equal to the dose interval of the assay.

Fungicide sensitivity distributions. $\log \mathrm{ED}_{50}$ values for each fungicide were distributed normally within each population, except those for triadimenol within the $\mathrm{Bb}$ and $\mathrm{Nb}$ populations; these two distributions were similar according to the Kolmogorov-Smirnoff two-sample test (Genstat, Lawes Agricultural Trust, Hertfordshire, England). Furthermore, distributions of sensitivities to each individual fungicide exhibited homogeneity of variance with respect to each $\mathrm{Bb}$ and $\mathrm{Nb}$ population pair and each $\mathrm{Dr}$ and $\mathrm{Rr}$ pair. Therefore, sensitivity data for individual fungicides were combined for each pair to form single composite samples representative of an unexposed population (termed "unexposed") and a population with practical resistance to triadimefon (termed "selected").

Triadimenol sensitivity distributions were markedly different for the unexposed versus selected populations (Fig. 1). Whereas $\sim 75 \%$ of the unexposed isolates had $\mathrm{ED}_{50}$ values in the range of 0.02 to $0.18 \mu \mathrm{g} / \mathrm{ml}$, none of the 82 isolates from the selected population showed this level of sensitivity. Rather, more than $80 \%$ of the isolates from the selected population had $\mathrm{ED}_{50}$ values in the range of 0.56 to $5.6 \mu \mathrm{g} / \mathrm{ml}$, and a few were as high as 5.6 to $17.8 \mu \mathrm{g} / \mathrm{ml}$. A similar, but less pronounced, shift was noted for the distribution of sensitivities to myclobutanil (Fig. 1). For instance, nearly $75 \%$ of the isolates from the unexposed population had $\mathrm{ED}_{50}$ values $\leq 0.06 \mu \mathrm{g} / \mathrm{ml}$, compared to $1 \%$ of the isolates from the selected population with a similar level of sensitivity. In contrast, nearly $65 \%$ of isolates from the selected population had $\mathrm{ED}_{50}$ values $\geq 0.18 \mu \mathrm{g} / \mathrm{ml}$, compared to $\sim 10 \%$ of the unexposed isolates. The selected population was only slightly less sensitive to fenarimol than the unexposed population, with sixfold fewer isolates having $\mathrm{ED}_{50}$ values $\leq 0.02 \mu \mathrm{g} / \mathrm{ml}$ and almost threefold more isolates having $\mathrm{ED}_{50}$ values $\geq 0.06 \mu \mathrm{g} / \mathrm{ml}$ (Fig. 1). The relative magnitude of these population shifts is illustrated by the ratio of the median $\mathrm{ED}_{50}$ values for each fungicide within the selected versus unexposed populations, i.e., 32, 7.7, and 2.3 for triadimenol, myclobutanil, and fenarimol, respectively (Table 4).

TABLE 4. Means, medians, and standard deviations of the 50\% effective dose $\left(\mathrm{ED}_{50}\right)$ measurements of sensitivity to triadimenol, myclobutanil, and fenarimol among unexposed and selected populations of Uncinula necator

\begin{tabular}{lccccc}
\hline & \multicolumn{2}{c}{ Mean $(\mu \mathrm{g} / \mathrm{ml})$} & & \multicolumn{2}{c}{ Median $(\mu \mathrm{g} / \mathrm{ml})$} \\
\cline { 2 - 3 } \cline { 5 - 6 } Fungicide & Unexposed $^{\mathrm{y}}$ & Selected $^{\mathrm{z}}$ & & Unexposed & Selected \\
\hline Triadimenol & 0.09 & 1.8 & & 0.06 & 1.9 \\
Myclobutanil & 0.03 & 0.25 & & 0.03 & 0.23 \\
Fenarimol & 0.03 & 0.07 & & 0.03 & 0.07 \\
\hline
\end{tabular}

y Pooled data from Burdette and Naples, NY, vineyards, $n=77$.

${ }^{\mathrm{z}}$ Pooled data from Dresden and Geneva, NY, vineyards, $n=82$.
Cross-resistance. The degree of cross-resistance among the three DMI fungicides was analyzed by two different methods. In the first, all isolates from both the unexposed and selected populations were combined, then individual $\log \mathrm{ED}_{50}$ values for each fungicide were regressed against the same isolate's $\log \mathrm{ED}_{50}$ values for the remaining two fungicides and examined for correlation (Minitab) (Fig. 2). Based on this analysis, the correlation in sensitivities was strongest between triadimenol and myclobutanil $(r=0.85)$, less between myclobutanil and fenarimol $(r=0.73)$, and least between triadimenol and fenarimol $(r=0.56)$. All three correlations were significant at $P<0.001$; the correlation between triadimenol and fenarimol was significantly less than the correlation between triadimenol and myclobutanil $(P<0.001)$ or myclobutanil and
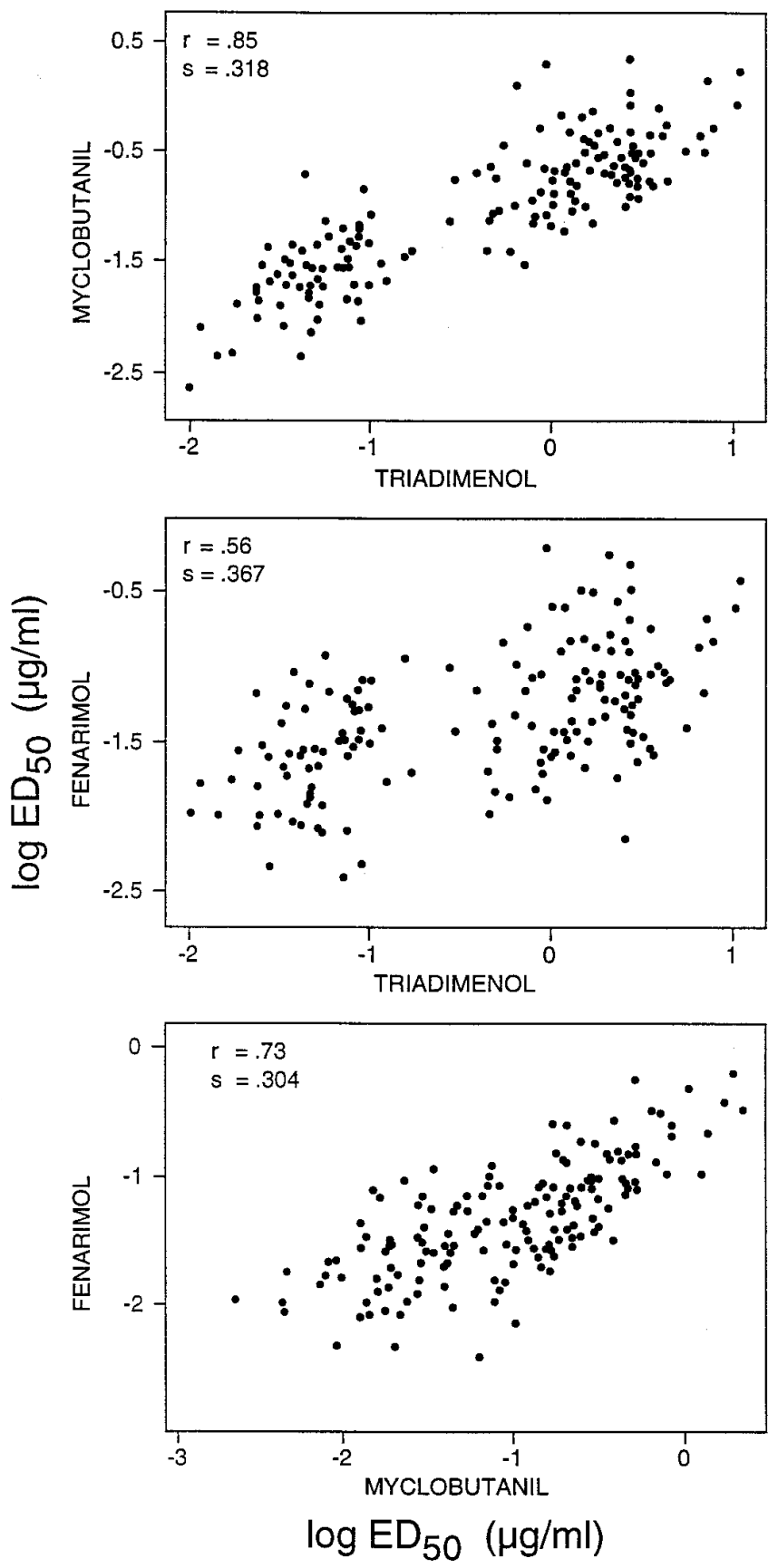

Fig. 2. Scattergrams depicting correlations among the log $50 \%$ effective dose $\left(\mathrm{ED}_{50}\right)$ values relative to triadimenol, myclobutanil, and fenarimol for individual Uncinula necator isolates within the combined unexposed (Burdette and Naples, NY) and selected (Dresden and Geneva, NY) grapevine populations $(n=159)$. 
fenarimol $(P<0.001)$. The difference in correlations between myclobutanil and fenarimol versus myclobutanil and triadimenol was significant at $P=0.11$.

The second analytical method was reserved for a comparison of isolates in sensitivity categories that were classified as resistant based on their pronounced frequency increases (relative to unexposed populations) in vineyards with a history of DMI use and in which triadimefon no longer provided acceptable control of powdery mildew. Thus, such frequency increases were interpreted as demonstrations of resistance to DMI fungicides, i.e., the advantaged responses of the proliferating phenotypes to the selection pressure provided by DMI applications. This criterion for determining the sensitivity level that confers resistance to a DMI fungicide recently was proposed and validated by Köller et al. (17) who were working with Venturia inaequalis. Specific $\mathrm{ED}_{50}$ values used for classifying $U$. necator isolates as resistant to triadimenol, myclobutanil, or fenarimol were $>0.56,>0.18$, and $>0.18 \mu \mathrm{g} / \mathrm{ml}$, respectively (Fig. 1). The 82 isolates from the Selected population were examined individually for their concomitant classification as resistant or not resistant to each DMI; the relationships were displayed as a Venn diagram (Fig. 3). Based on this criterion, 93, 65, and $17 \%$ of the isolates were considered resistant to triadimenol, myclobutanil, and fenarimol, respectively. Of the 76 isolates classified as resistant to triadimenol, 64\% were classified as crossresistant to myclobutanil, $18 \%$ as cross-resistant to fenarimol, and $17 \%$ as cross-resistant to both. Of the isolates classified as resistant to myclobutanil, $25 \%$ were classified as cross-resistant to fenarimol. Of all the isolates classified as resistant to myclobutanil or fenarimol, $95 \%$ were classified as cross-resistant to triadimenol.

\section{DISCUSSION}

In this study, we developed a method for recovering, maintaining, and repeatedly assaying a collection of nearly 160 monoconidial isolates of $U$. necator for their sensitivities to DMI fungicides. This method allowed us to determine, with a known measure of precision, the distribution of sensitivities among individual isolates representing (i) a population with no previous exposure to DMIs and (ii) a population with practical resistance to triadimefon but not to myclobutanil or fenarimol. It also allowed us to compare shifts in the sensitivity of isolates to each DMI with the degree of powdery mildew control provided when the fungicide is applied to the shifted population and to examine the cross-resistance relationships within different segments of the populations. Although a variety of methods have been used previously to assay isolates of $U$. necator for DMI fungicide resistance $(9,10,18,39-$ $41)$, smaller sample sizes (10,39-41), heterogeneous subcultures $(9,10,39,40)$, unknown or unreported levels of precision, and a lack of associated disease control data, heretofore, have precluded many of the studies presented in the current report.

Whereas low rates (35 to $70 \mathrm{~g} / \mathrm{ha}$ ) of triadimefon applied at 21-day intervals provided nearly complete control of powdery mildew when it was registered as the first DMI fungicide for grapes during the early 1980s (31), more recently labeled rates of 105 to $175 \mathrm{~g} / \mathrm{ha}$ applied at 10- to 14-day intervals often have provided $<50 \%$ control in the Dr and $\mathrm{Rr}$ (selected) vineyards (Tables 1 and 2). This diminution of disease control efficacy is associated with an $\sim 30$-fold increase in median $\mathrm{ED}_{50}$ values for triadimenol in the selected versus unexposed populations of $U$. necator, which presumably represents the magnitude of shift that has occurred within the selected vineyards since DMIs were first introduced. Because triadimefon provided suboptimal control for several years prior to the sensitivity assays, it is not possible to determine the magnitude of the shift that occurred when disease control first began to wane. However, it is interesting to note that median sensitivities to fenarimol and myclobutanil in the selected population have shifted only by factors of $\sim 2$ and 8 , respectively, and that labeled rates of these fungicides still provided good control in both vineyards when tested the year before the sensitivity assays were conducted and in the $\mathrm{Rr}$ vineyard when tested the year after (Tables 1 and 2).

Classifying isolates of Venturia inaequalis as resistant to DMI fungicides according to the criterion we used for U. necator, Köller et al. (17) reported that apple scab control was compromised in orchards when the proportion of isolates resistant to fenarimol and myclobutanil exceeded $\sim 40 \%$; they also reported that labeled rates of these fungicides provided $\sim 50$ to $75 \%$ control when treated plants were challenged with a resistant isolate. Thus, we speculate that the sensitivity distribution for myclobutanil within the selected population, where $65 \%$ of isolates were categorized as resistant sensu Köller et al. (17), may represent a threshold condition with respect to the development of practical resistance to this fungicide. Under this model, the presumed partial control of resistant isolates provided by labeled rates of myclobutanil will no longer restrict mean disease severity to acceptable levels if the sensitivity shift continues or if rates of the fungicide are lowered either intentionally or inadvertently by poor spray coverage. Results from the Dr vineyard in 1996, when six seasonal applications of myclobutanil at $56 \mathrm{~g} / \mathrm{ha}$ provided $\sim 40 \%$ less powdery mildew control than the labeled rate of $112 \mathrm{~g} / \mathrm{ha}$, supports this hypothesis (W. Wilcox, E. Erickson, and D. Riegel, unpublished data).

Although poor field performance of triadimefon was the basis for this study, we assayed for sensitivities to triadimenol rather than triadimefon for technical reasons and because the former chemical is the reduced, active form of the fungicide in the plant and fungus. Because the speed and efficiency of conversion from triadimefon to triadimenol at the site of the Vitis- $U$. necator interaction is unknown, it is possible that applications of a given rate of triadimefon result in quantitatively lower levels of pathogen expo-

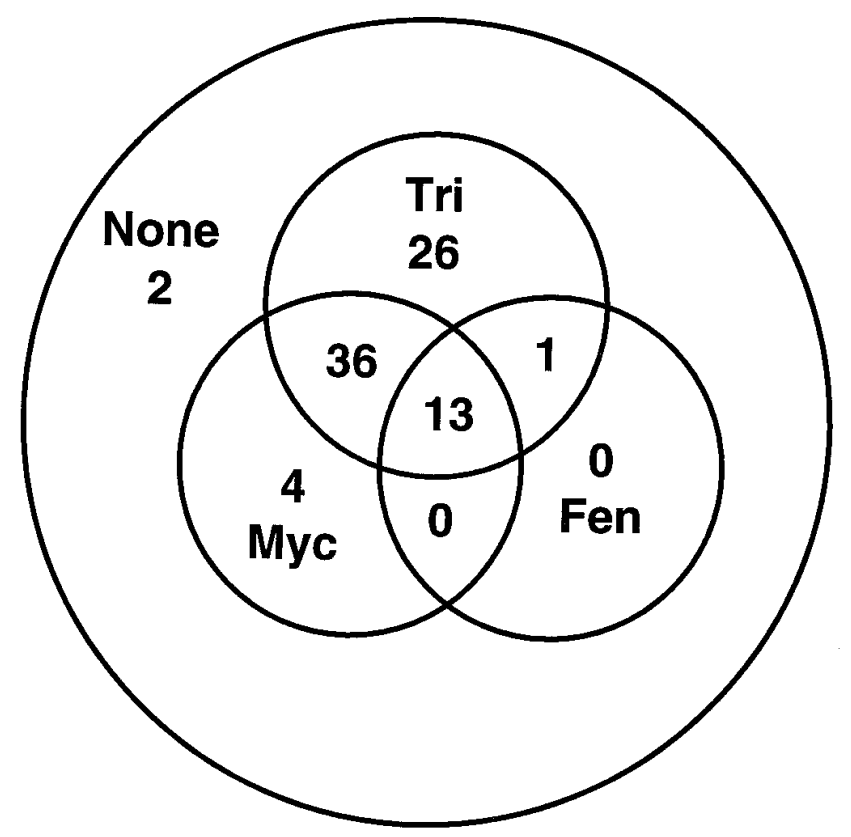

Fig. 3. Venn diagram depicting the three-way comparison of resistance to triadimenol (Tri), myclobutanil (Myc), and fenarimol (Fen) among Uncinula necator isolates within the combined Dresden and Geneva, NY (selected), population. An isolate was identified as resistant to a fungicide if its $50 \%$ effective dose $\left(E_{50}\right)$ value placed it in a sensitivity category with a pronounced frequency increase relative to the composite unexposed population (Burdette and Naples, NY). Specific $\mathrm{ED}_{50}$ values classifying isolates as resistant to triadimenol, myclobutanil, or fenarimol were $>0.56,>0.18$, and $>0.18$ $\mu \mathrm{g} / \mathrm{ml}$, respectively. The large circle represents the full set of 82 isolates from the selected population; each smaller circle represents the set of isolates with $\mathrm{ED}_{50}$ values classifying them as resistant to the indicated fungicide(s) according to the above criteria. Numbers within the circles denote the number of individual isolates within each indicated subset. Two isolates were classified as resistant to none of the three fungicides. 
sure to active triadimenol. For instance, Gubler et al. (9) have reported mean $\mathrm{ED}_{50}$ values of $1.4,0.15$, and $0.13 \mu \mathrm{g} / \mathrm{ml}$ for triadimefon, myclobutanil, and fenarimol, respectively, in an assay of 60 subcultures of $U$. necator from a wild-type population in California. Whereas these $\mathrm{ED}_{50}$ values for myclobutanil and fenarimol were similar to those we determined in the unexposed New York population (i.e., mean values of $0.03 \mu \mathrm{g} / \mathrm{ml}$ for both fungicides), we found the mean $\mathrm{ED}_{50}$ value for triadimenol in the unexposed population $(0.09 \mu \mathrm{g} / \mathrm{ml})$ to be substantially lower than that reported for triadimefon in the California wild-type population. Although differences in assay techniques may have contributed to some absolute differences in the $\mathrm{ED}_{50}$ values determined in the two studies, it is noteworthy that (i) both groups determined that mean sensitivities to myclobutanil and fenarimol were equivalent in their respective unexposed populations, yet (ii) the mean triadimefon $\mathrm{ED}_{50}$ was $\sim 10$-fold greater than that of myclobutanil and fenarimol in the California study, whereas the mean triadimenol $\mathrm{ED}_{50}$ was only threefold greater than that of myclobutanil and fenarimol in our study.

If these data reflect incomplete conversion of triadimefon to triadimenol after fungicide applications to grape tissue, it would suggest that environmental or metabolic factors influencing this process could affect the concentration of the active ingredient to which the pathogen is exposed in the field. Lowering the application rate of DMI fungicides accelerates the selection of resistant phenotypes of Venturia inaequalis in apple orchards by increasing the isolates' abilities to withstand the application and multiply (14). It is likely that low effective (active form) rates of DMIs similarly select for the more resistant members of $U$. necator populations in grape vineyards. For instance, Gubler et al. (9) suggested that the differences in sensitivity shifts for triadimefon relative to those for fenarimol and myclobutanil in California vineyards were due in part to the lower inherent activity of triadimefon relative to the other two fungicides.

The two methods we used to assess cross-resistance within $U$. necator each have specific advantages and limitations. By examining all isolates from combined unexposed and selected populations, correlation analysis might be considered alternatively to have assessed the cross-sensitivity relationships between different pairs of fungicides, because it compared isolates from the most sensitive to the most resistant ends of the spectra. This method has the advantages of maximizing sample size and removing any possible source of subjectivity or arbitrariness in determining which isolates to analyze. However, by giving equal weight to the responses of all isolates regardless of their fungicide sensitivities, it introduces extraneous data into analysis of the question of greatest practical import: will an isolate that is poorly controlled by one fungicide also be poorly controlled by others? In contrast, the analysis presented in the Venn diagram (Fig. 3) not only allowed three-way comparisons of individual isolate sensitivities to triadimenol, myclobutanil, and fenarimol, but also was confined to examining isolates considered resistant to one or more of the fungicides in question. However, the terms "resistant" and "sensitive" are discrete, qualitative descriptors of a response to fungicide dose that is continuous and quantitative. Because the nature of this response provides no prima facie definition of resistance on a practical level, we applied a recently validated (17) criterion based on the apparent selection of $U$. necator phenotypes within a poorly controlled population after prolonged DMI exposure. Both this method and the correlation analysis indicated a substantially greater degree of cross-resistance between triadimenol and myclobutanil than between either of these fungicides and fenarimol. However, the Venn diagram was easier to interpret conceptually, e.g., $25 \%$ of the isolates classified as resistant to myclobutanil also were resistant to fenarimol in the Venn diagram, whereas a correlation coefficient of 0.73 was obtained when $\log \mathrm{ED}_{50}$ values of these two fungicides were compared. Thus, we believe that although both methods led to generally similar conclusions, the Venn dia- gram produced a more useful and focused analysis, the limitations of defining resistance notwithstanding.

The restricted levels of cross-resistance indicated by these data, particularly between fenarimol and the two other fungicides, is in sharp contrast to the generally high levels of cross-resistance documented among many different DMIs for isolates of Venturia inaequalis $(11,15,17)$. An explanation for this phenomenon was not investigated, but it is possible that resistance to DMIs is a multigenic trait in $U$. necator and that one or more resistance genes are independent with respect to individual DMIs or groupings thereof, as has been demonstrated for Pyrenophora teres (32). This model could account partially for the different magnitudes of the shifts in sensitivity to triadimenol, myclobutanil, and fenarimol in the selected vineyards after extensive use of triadimefon throughout the 1980s, although the more recent use of additional DMIs in these vineyards must be acknowledged. Regardless of the mechanism, this finding has significant implications with respect to programs for control of grapevine powdery mildew and DMI resistance management. If triadimefon-resistant isolates of $U$. necator are indeed less cross-resistant to fenarimol than to myclobutanil under typical field conditions, sensitivity shifts toward practical resistance to fenarimol should proceed more slowly than shifts toward myclobutanil resistance where such isolates predominate, assuming equivalent use programs of the respective fungicides. Similarly, if cross-resistance between fenarimol and myclobutanil is incomplete, using these materials in alternation may reduce selection pressure for practical resistance development relative to use of one or the other exclusively. However, control of a $U$. necator isolate by a DMI fungicide is influenced by a complex of factors, including the rate and intrinsic activity of the fungicide applied, its absorption and mobility within grape tissues, and its susceptibility to photo- and biotic degradation. Thus, the practical significance of apparent differences in cross-resistance among these and other DMI fungicides can be determined conclusively only by monitoring shifts in sensitivity distributions and fungicide performances in relevant field experiments.

\section{ACKNOWLEDGMENTS}

This work was supported in part by the New York State Wine and Grape Foundation, Penn Yan, NY, and by H \& I Agritech, Ithaca, NY. We thank D. Riegel for providing disease control data from the Dresden, NY, vineyard, J. Barnard for statistical assistance, W. Köller and D. Gadoury for stimulating discussions, and A. Lewis and A. Prestia for technical help.

\section{LITERATURE CITED}

1. Buchenauer, H. 1976. Studies on the systemic activity of Bayleton (triadimefon) and its effect against certain fungal diseases of cereals. Pflanzenschutz-Nachr. 29:266-280.

2. Clark, T., Clifford, D. R., Deas, A. H. B., Gendle, P., and Watkins, D. A. M. 1978. Photolysis, metabolism and other factors influencing the performance of triadimefon as a powdery mildew fungicide. Pestic. Sci. 9:497506.

3. De Waard, M. A. 1994. Resistance to fungicides which inhibit sterol $14 \alpha$ demethylation, an historical perspective. Pages 3-10 in: Fungicide Resistance: BCPC Monograph 60. S. Heaney, D. Slawson, D. W. Hollomon, M. Smith, P. E. Russell, and D. W. Parry, eds. British Crop Protection Council, Surrey, England.

4. Doster, M. A., and Schnathorst, W. C. 1985. Effects of leaf maturity and cultivar resistance on development of the powdery mildew fungus on grapevines. Phytopathology 75:318-321.

5. EPPO. 1988. Fungicide resistance: Definitions and use of terms. EPPO Bull. 18:569-574.

6. Erickson, E. O., and Wilcox, W. F. 1996. Distributions of sensitivities to three demethylation inhibitor fungicides among populations of Uncinula necator sensitive and resistant to triadimefon. (Abstr.) Phytopathology 86 (Suppl.):S31.

7. Finney, D. J. 1978. Statistical Method in Biological Assay. 3rd ed. Macmillan Publishing Co., Inc., New York.

8. Gasztonyi, M., and Josepovits, G. 1979. The activation of triadimefon and its role in the selectivity of fungicide action. Pestic. Sci. 10:57-65. 
9. Gubler, W. D., Ypema, H. L., Ouimette, D. G., and Bettiga, L. J. 1996. Occurrence of resistance in Uncinula necator to triadimefon, myclobutanil, and fenarimol in California grapevines. Plant Dis. 80:902-909

10. Heaney, S. P. 1991. A method for the examination of the sensitivity of Uncinula necator to DMI fungicides. EPPO Bull. 21:319-321.

11. Hildebrand, P. D., Lockart, C. L., Newberry, R. J., and Ross, P. G. 1989. Resistance of Venturia inaequalis to bitertanol and other demethylationinhibiting fungicides. Can. J. Plant Pathol. 10:311-316.

12. Jenkyn, J. F., Dyke, G. V., and Todd, A. D. 1983. Effects of fungicide movement between plots in field experiments. Plant Pathol. 32:311-324.

13. Köller, W. 1991. Fungicide resistance in plant pathogens. Pages 679-720 in: CRC Handbook of Pest Management in Agriculture. D. Pimentel and A. A. Hanson, eds. CRC Press, Boca Raton, FL.

14. Köller, W. 1996. Recent developments in DMI resistance. Pages 301-311 in: Modern Fungicides and Antifungal Compounds. H. Lyr, P. E. Russell, and H. D. Sisler, eds. Intercept Press, Ltd., Andover, England.

15. Köller, W., Parker, D. M., and Reynolds, K. L. 1991. Baseline sensitivities of Venturia inaequalis to sterol demethylation inhibitors. Plant Dis. 75:726-728.

16. Köller, W., and Scheinpflug, H. 1987. Fungal resistance to sterol biosynthesis inhibitors: A new challenge. Plant Dis. 71:1066-1074.

17. Köller, W., Wilcox, W. F., Barnard, J., Jones, A. L., and Braun, P. G. 1997. Detection and quantification of resistance of Venturia inaequalis populations to sterol demethylation inhibitors. Phytopathology 87:184-190.

18. Küng, R. 1991. Test method for examination of the sensitivity of Uncinula necator to pyrifenox. EPPO Bull. 21:317-319.

19. Lakso, A. N., Pratt, C., Pearson, R. C., Pool, R. M., Seem, R. C., and Welser, M. J. 1982. Photosynthesis, transpiration, and water use efficiency of mature grape leaves infected with Uncinula necator (powdery mildew). Phytopathology 72:232-236.

20. Ough, C. S., and Berg, H. W. 1979. Powdery mildew sensory effect on wine. Am. J. Enol. Vitic. 30:321.

21. Ouimette, D. G., and Gubler, W. D. 1990. Sensitivity of grape powdery mildew isolates from California towards fenarimol, myclobutanil, and triadimefon. (Abstr.) Phytopathology 80:975.

22. Pearson, R. C., and Gadoury, D. M. 1987. Cleistothecia, the source of primary inoculum for grape powdery mildew in New York. Phytopathology 77:1509-1514.

23. Pearson, R. C., and Gadoury, D. M. 1992. Powdery mildew of grape. Pages 129-146 in: Plant Diseases of International Importance. Vol. 3, Diseases of Fruit Crops. J. Kumar, H. S. Chaube, U. S. Singh, and A. N. Mukhopadhyay, eds. Prentice Hall, Englewood Cliffs, NJ.

24. Pearson, R. C., and Riegel, D. G. 1990. Evaluation of fungicides for control of powdery mildew of grapes, 1989. Fungic. Nematic. Tests 45:73

25. Pearson, R. C., and Riegel, D. G. 1991. Evaluation of fungicides for control of powdery mildew of grapes, 1990. Fungic. Nematic. Tests 46:89.

26. Pearson, R. C., and Riegel, D. G. 1992. Evaluation of fungicides for control of powdery mildew of grapes, 1991. Fungic. Nematic. Tests 47:65.

27. Pearson, R. C., and Riegel, D. G. 1993. Evaluation of fungicides for control of powdery mildew of grapes, 1992. Fungic. Nematic. Tests 48:79.

28. Pearson, R. C., and Riegel, D. G. 1994. Evaluation of fungicides for con- trol of powdery mildew of grapes, 1993. Fungic. Nematic. Tests 49:70.

29. Pearson, R. C., and Riegel, D. G. 1995. Evaluation of fungicides for control of powdery mildew of grapes, 1994. Fungic. Nematic. Tests 50:74.

30. Pearson, R. C., Riegel, D. G., and Gadoury, D. M. 1994. Control of powdery mildew in vineyards using single-application vapor-action treatments of triazole fungicides. Plant Dis. 78:164-168.

31. Pearson, R. C., and Taschenberg, E. F. 1982. Evaluation of Bayleton for control of powdery mildew of grapes, 1981. Fungic. Nematic. Tests 37:48.

32. Peever, T. L., and Milgroom, M. G. 1993. Genetic correlations in resistance to sterol biosynthesis-inhibiting fungicides in Pyrenophora teres. Phytopathology 83:1076-1082.

33. Pool, R. M., Pearson, R. C., Welser, M. J., Lakso, A. N., and Seem, R. C. 1984. Influence of powdery mildew on yield and growth of Rosette grapevines. Plant Dis. 68:590-593.

34. Scheinpflug, H., Paul, V., and Kraus, P. 1978. Studies on the mode of action of Bayleton against cereal diseases. Pflanzenschutz-Nachr. 31:101115.

35. Sisler, H. D., and Ragsdale, N. N. 1989. Molecular design and target site analysis in fungicide development. Pages 198-214 in: Probing Bioactive Mechanisms. P. S. Magee, D. R. Henry, and J. H. Block, eds. American Chemical Society, Washington, DC.

36. Skylakakis, G. 1987. Changes in the composition of pathogen populations caused by resistance to fungicides. Pages 227-237 in: Populations of Plant Pathogens: Their Dynamics and Genetics. M. S. Wolfe and C. E. Caten, eds. Blackwell Scientific Publications, Oxford.

37. Skylakakis, G., and Hollomon, D. W. 1987. Epidemiology of fungicide resistance. Pages 94-103 in: Combating Resistance to Xenobiotics. M. G. Ford, D. W. Hollomon, B. P. S. Khambay, and R. M. Sawicki, eds. Ellis Horwood, Chichester, England.

38. Smith, F. D., Parker, D. M., and Köller, W. 1991. Sensitivity distribution of Venturia inaequalis to the sterol demethylation inhibitor flusilazole: Baseline sensitivity and implications for resistance monitoring. Phytopathology 81:392-396.

39. Steden, C., Forster, B., and Steva, H. 1994. Sensitivity of Uncinula necator to penconazole in European countries. Pages 97-101 in: Fungicide Resistance: BCPC Monograph No. 60. S. Heaney, D. Slawson, D. W. Hollomon, M. Smith, P. E. Russell, and D. W. Parry, eds. British Crop Protection Council, Surrey, England.

40. Steva, H. 1994. Evaluating anti-resistance strategies for control of Uncinula necator. Pages 59-66 in: Fungicide Resistance: BCPC Monograph No. 60. S. Heaney, D. Slawson, D. W. Hollomon, M. Smith, P. E. Russell, and D. W. Parry, eds. British Crop Protection Council, Surrey, England.

41. Steva, H., and Clerjeau, M. 1990. Cross resistance to sterol biosynthesis inhibitor fungicides in strains of Uncinula necator isolated in France and Portugal. Med. Fac. Landbouww. Rijksuniv. Gent 55:983-988.

42. Travis, J. W., and Muza, A. J. 1991. Evaluation of disease management strategies for the control of Bayleton resistant Uncinula necator on grapes, 1990. Fungic. Nematic. Tests 46:94-95.

43. Wilcox, W. F., and Riege,. D. G. Evaluation of fungicide programs for control of grapevine powdery mildew, 1996. Fungic. Nematic. Tests. In press. 